University of Wollongong

Research Online

Australian Institute for Innovative Materials -

Papers

Australian Institute for Innovative Materials

$1-1-2016$

The effect of treatment time on the ionic liquid surface film formation:

promising surface coating for Mg alloy AZ31

Yafei Zhang

Deakin University

Xiao Liu

University of Wollongong, xiaol@uow.edu.au

Sina S. Jamali

University of Wollongong, sjamali@uow.edu.au

Bruce Prof Bruce Hinton

Deakin University

Simon E. Moulton

University of Wollongong, smoulton@uow.edu.au

See next page for additional authors

Follow this and additional works at: https://ro.uow.edu.au/aiimpapers

Part of the Engineering Commons, and the Physical Sciences and Mathematics Commons

Research Online is the open access institutional repository for the University of Wollongong. For further information contact the UOW Library: research-pubs@uow.edu.au 


\title{
The effect of treatment time on the ionic liquid surface film formation: promising surface coating for Mg alloy AZ31
}

\author{
Abstract \\ $\mathrm{Mg}$ alloys are attractive materials for medical devices. The main limitation is that they are prone to \\ corrosion. A low toxicity surface coating that enables uniform, controlled corrosion at a desired rate (this \\ usually means it must offer barrier functions for a limited time period) is desirable. Phosphate-based \\ ionic liquids (ILs) are known to induce a coating that can reduce the corrosion rate of $\mathrm{Mg}$ alloys, \\ Furthermore, some ILs are known to be biocompatible and therefore, controlling the corrosion behaviour \\ of an $\mathrm{Mg}$ alloy and its surface biocompatibility can be achieved through adding an appropriate low toxic IL \\ surface layer to the substrate. In this study, we have evaluated the cytotoxicity of three phosphate-based \\ ILs to primary human coronary artery endothelial cells. Among them, tributyl(methyl)-phosphonium \\ diphenylphosphate ( $\mathrm{P} 1,4,4,4 \mathrm{dpp})$ shows the lowest cytotoxicity. Therefore, further work was aimed at \\ developing an appropriate treatment method to produce a homogeneous and passive surface coating \\ based on P1,4,4,4dpp IL, with the focus on investigating the effect of treatment time. The results showed \\ that that the formation of IL coating on AZ31 has proceeded progressively, and treatment time plays an \\ important role. An IL treatment at $100^{\circ} \mathrm{C}$ with an extended treatment time of $5 \mathrm{~h}$ significantly enhanced \\ corrosion resistance of the AZ31 alloy in simulated body fluid. Additionally, the corrosion morphology was \\ uniform and there was no evidence of "localized pitting corrosion" observed. Such a performance makes \\ this ionic liquid coating as a potential surface coating biodegradable Mg-based implants.

\section{Disciplines} \\ Engineering | Physical Sciences and Mathematics

\section{Publication Details} \\ Zhang, Y., Liu, X., Jamali, S. S., Hinton, B. R.W., Moulton, S. E., Wallace, G. G. \& Forsyth, M. (2016). The \\ effect of treatment time on the ionic liquid surface film formation: promising surface coating for $\mathrm{Mg}$ alloy \\ AZ31. Surface and Coatings Technology, 296 192-202.

\section{Authors} \\ Yafei Zhang, Xiao Liu, Sina S. Jamali, Bruce Prof Bruce Hinton, Simon E. Moulton, Gordon G. Wallace, and \\ Maria Forsyth
}


The Effect of Treatment Time on the Ionic Liquid Surface Film Formation: Promising Surface Coating for Mg Alloy AZ31

Yafei Zhang ${ }^{\dagger,}$, Xiao Liu ${ }^{\ddagger}, \S$, Sina S. Jamali ${ }^{\ddagger}$, Bruce R. W. Hinton ${ }^{\dagger}$, Simon E. Moulton ${ }^{\ddagger}$, , Gordon G. Wallace ${ }^{\ddagger \S}$, Maria Forsyth ${ }^{* \dagger, \ddagger}$

${ }^{\dagger}$ Institute for Frontier Materials, Deakin University, 221 Burwood Highway, Burwood, Victoria, 3125 Australia

${ }^{\ddagger}$ Australian Research Council Centre of Excellence for Electromaterials Science, Australia ${ }^{\S}$ Intelligent Polymer Research Institute, University of Wollongong, Wollongong, NSW, Australia

Yafei Zhang: yafei.zhang@deakin.edu.au Xiao Liu: xiaol@uow.edu.au

Sina S. Jamali: ssj198@uow.edu.au

Bruce R.W. Hinton: bruce.hinton@deakin.edu.au

Simon E. Moulton: smoulton@,swin.edu.au

Gordon G. Wallace: gwallace@uow.edu.au

Maria Forsyth: maria.forsyth@deakin.edu.au

\section{*Corresponding Author}

Email: maria.forsyth@ deakin.edu.au. Tel: +61 392446727. Fax: +61 392446868

Present Address 
Institute for Frontier Materials, Deakin University Burwood Campus, Building Hi, 221 Burwood Highway, Burwood, Victoria 3125 Australia. 


\section{ABSTRACT}

$\mathrm{Mg}$ alloys are attractive materials for medical devices. The main limitation is that they are prone to corrosion. A low toxicity surface coating that enables uniform, controlled corrosion at a desired rate (this usually means it must offer barrier functions for a limited time period) is desirable. Phosphate-based ionic liquids (ILs) are known to induce a coating that can reduce the corrosion rate of Mg alloys, Furthermore, some ILs are known to be biocompatible and therefore, controlling the corrosion behaviour of an $\mathrm{Mg}$ alloy and its surface biocompatibility can be achieved through adding an appropriate low toxic IL surface layer to the substrate. In this study, we have evaluated the cytotoxicity of three phosphate-based ILs to primary human coronary artery endothelial cells. Among them, tributyl(methyl)-phosphonium diphenylphosphate $\left(\mathrm{P}_{1,4,4,4} \mathrm{dpp}\right)$ shows the lowest cytotoxicity. Therefore, further work was aimed at developing an appropriate treatment method to produce a homogeneous and passive surface coating based on $\mathrm{P}_{1,4,4,4} \mathrm{dpp}$ IL, with the focus on investigating the effect of treatment time. The results showed that that the formation of IL coating on AZ31 has proceeded progressively, and treatment time plays an important role. An IL treatment at $100^{\circ} \mathrm{C}$ with an extended treatment time of 5 hours significantly enhanced corrosion resistance of the AZ31 alloy in simulated body fluid. Additionally, the corrosion morphology was uniform and there was no evidence of "localized pitting corrosion" observed. Such a performance makes this ionic liquid coating as a potential surface coating biodegradable Mg-based implants.

\section{KEYWORDS}

Biodegradable magnesium implants, Surface coating, Ionic liquid, SECM, Flow 


\section{INTRODUCTION}

In recent years, the study of degradable biomaterials has been at the forefront of biomaterials research. Magnesium (Mg) alloys are of interest as candidates for biodegradable devices (e.g. biodegradable coronary artery stents), because of (1) their well-known biocompatibility: $\mathrm{Mg}$ is one of the most abundant elements naturally present in the human body; (2) the fast degradability of Mg alloys in the human body; (3) their excellent mechanical properties: the density and Young's Modulus ( $\left.\rho=1.74 \mathrm{~g} / \mathrm{cm}^{2}, \mathrm{E}=45 \mathrm{GPa}\right)$ are similar to these of natural bones ( $\rho=1.75 \mathrm{~g} / \mathrm{cm}^{2}, \mathrm{E}=40-57 \mathrm{GPa}$ ), and their strength can be up to $330 \mathrm{Mpa}$, which is sufficient to maintain the opening of a diseased artery.[1,2]

However, there are only a few commercially available $\mathrm{Mg}$ alloy based devices in the market. A major limitation with respect to the clinical application of $\mathrm{Mg}$ alloys is the fact that corrosion is too rapid in the body, leading to the generation of hydrogen bubbles and a localized $\mathrm{pH}$ increase that may damage the surrounding tissues.[3] Additionally, the $\mathrm{Mg}$ alloys have a strong tendency for localized corrosion.[3, 4] This localized corrosion can lead to the early loss of mechanical integrity, and thus premature failure before the implant can achieve its purpose.[3] Another concern is the interactions between the interface of the implant and the host tissue. For example in the case of stent implants used for heart conditions, in-stent restenosis and thrombosis could occur due to the clot formation (i.e. accumulation of proteins from the blood) and cell proliferation on a stent surface. $[5,6]$

One method for overcoming this issue has been the use of corrosion protective and low toxicity surface coatings, which can (1) offer barrier functions for a limited time period and lead to uniform corrosion as opposed to localised pitting, and (2) increase the biocompatibility of the $\mathrm{Mg}$ alloy. Popular techniques for the development of corrosion resistive and biocompatible surface coatings for $\mathrm{Mg}$ and $\mathrm{Mg}$ alloys have been previously reviewed.[7-10] Although some promising techniques related to this field have been studied in recent years, in 
many cases satisfactory solutions still do not exist, and thus no commercial coatings are available in the biomedical devices sector. Further in-depth research is still needed to develop better, simpler and cheaper coatings for $\mathrm{Mg}$ and its alloys.

In recent years, ionic liquids (ILs) as low melting organic salts have shown attractive properties that are favourable when designing surface coatings for $\mathrm{Mg}$ alloys. They have a high concentration of reactive species, and can be highly stable. ILs with anions such as (bis(trifluoromethylsulfonyl)imide $\left(\mathrm{NTf}_{2}^{-}\right)[2,11]$ and diphenylphosphate $\left(\mathrm{dpp}^{-}\right)[12,13]$, have been shown to form a surface film on a range of $\mathrm{Mg}$ alloys. These anions play an important role in the formation of a protective film.

As well as this, the use of ILs has opened up opportunities in life science. For example, ILs act as protein-stabilizing agents,[14] and can be solvents for enzymes.[15] In addition, ILs have been highlighted for their potential use as pharmaceuticals[16] and antimicrobials.[17] On the other hand, it has been suggested that ILs with at least one long hydrogen lipophilic substituent on the cation, (making the ILs relatively hydrophobic), can disrupt the membrane of bacterial cells, and cause the death of the cells.[17] Inspired by these prior works, it would appear that control over the corrosion performance coupled with surface biocompatibility of an $\mathrm{Mg}$ alloy implant may be achieved through control of IL chemistry and IL treatment processes.

Phosphate-based ILs are an attractive family for biodegradable Mg alloy devices, due to the reactivity of phosphate with $\mathrm{Mg}$ alloys, the absence of toxic atoms (e.g. fluorine in $\mathrm{NTf}_{2}[18$, 19]) in the anion atoms, and the attractive prospect of a range of inexpensive ILs. Recent works have shown that these ILs can react with $\mathrm{Mg}$ and $\mathrm{Mg}$ alloys to form surface films, which reduce corrosion in high humidity and chloride containing environments to some extent. $[12,13,20]$ However, it is challenging to form uniform and homogeneous surface films due to the complex morphology and microstructure of $\mathrm{Mg}$ alloy systems, and the 
protective nature of formed IL films on Mg alloys can be variable. To date an optimum IL treatment method for $\mathrm{Mg}$ alloys has not been developed despite promising preliminary work.[2, 11-13, 20, 21]

The interaction mechanism between phosphonium IL and $\mathrm{Mg}$ alloy surface has been investigated; during the IL treatment process, the phosphonium containing anion would undergo chemical reaction with the $\mathrm{O}-\mathrm{H}$ groups on the $\mathrm{Mg}$ surface to form metal ester $[\mathrm{Mg}$ O- $\left.\mathrm{PO}_{2}^{-}\right]$and release $\mathrm{H}_{2} \mathrm{O}$ molecules.[2, 12] In addition, we have previously[13] proposed that increasing the treatment temperature results in a thicker IL film on the surface, and explained this as due to the rate of chemical reactions/depositions being accelerated by a higher treatment temperature, which leads to more IL reaction products deposited on the surface. Building upon these studies, it is assumed that a more homogeneous IL surface film could be possibly achieved by either accelerating the chemical reaction rate or prolonging the reaction time.

Preliminary studies into the cytotoxicity of the phosphonium containing ILs (trihexyl(tetradecyl)phosphonium diphenylphosphate $\quad\left(\mathrm{P}_{6.6 .6 .14} \mathrm{dpp}\right)$, trihexyl(tetradecyl)phosphonium bis(2,4,4-trimethyl-pentyl)phosphinate $\left(\left[\mathrm{P}_{6.66614}\right]\left[\left({ }^{\mathrm{i}} \mathrm{C}_{8}\right)_{2} \mathrm{PO}_{2}\right]\right)$, tributyl(methyl)phosphonium diphenyphosphate $\left.\left(\mathrm{P}_{1,4,4,4} \mathrm{dpp}\right)\right)$ have been carried out.[22] However, in that study, stainless steel (SS) was chosen as the testing substrate. The SS substrates were treated with ILs, and then immersed in the cell culture media containing coronary artery cells for cytotoxicity tests. This approach has significant shortcomings; since SS is relatively inert and therefore there was an unknown amount of IL reacting (or simply adsorbing) on this substrate. With these considerations, further cytotoxicity test is considered necessary in order to examine the biocompatibility of these ILs.

In this work, a new approach to examine the toxicity of these three phosphonium-based ILs is performed by adding ILs directly to the cell culture. In addition, this work attempts to 
investigate an optimum IL treatment method, where emphasis is placed on investigating effect of treatment time at an elevated treatment temperature. An electrochemical impedance spectroscopy (EIS) technique using a pipette cell setup is used for the in-situ evolution of the IL coating formation process on $\mathrm{Mg}$ alloy $\mathrm{AZ31}$. Comprehensive surface characterizations are carried out to get insight into the formation process on the alloy surface. The corrosion performances of the samples are assessed by the combination of electrochemical tests, immersion tests and scanning electrochemical microscopy (SECM). In addition, considering $\mathrm{Mg}$ alloys are possible candidates for use as stents in a human coronary artery where the environment is constantly flowing, the corrosion performance of the IL coating is further evaluated under flowing conditions.

\section{Material and methods}

\subsection{Materials.}

The AZ31 alloy used in this study was cut from a direct strip cast ingot. The surface area of the samples was $5 \mathrm{~mm} \times 5 \mathrm{~mm}$. They were ground with $\mathrm{SiC}$ paper to a 4000 -mesh finish under running distilled water, and subsequently dried with nitrogen gas. Before each test, the sample was put into a vacuum desiccator for 1 hour to stabilize the native passive $\mathrm{MgO} / \mathrm{Mg}(\mathrm{OH})_{2}$ film.

Three ILs were of interest in this work. These ILs were trihexyl(tetradecyl)phosphonium diphenylphosphate $\quad\left(\mathrm{P}_{6,6,6,14} \mathrm{dpp}\right), \quad$ trihexyl(tetradecyl)phosphonium $\quad$ bis(2,4,4-trimethylpentyl)phosphinate $\left.\quad\left(\left[\mathrm{P}_{6,6,6,14}\right]\left[{ }^{\mathrm{i}} \mathrm{C}_{8}\right)_{2} \mathrm{PO}_{2}\right]\right), \quad$ and $\quad$ tributyl(methyl)phosphonium diphenyphosphate $\left(\mathrm{P}_{1,4,4,4} \mathrm{dpp}\right)$. The chemical structures of these ILs are shown in Figure 1. The $\mathrm{P}_{6,6,6,14} \mathrm{dpp}$ and $\mathrm{P}_{1,4,4,4} \mathrm{dpp}$ were synthesized in house, starting from trihexyl(tetradecyl)phosphonium chloride $\left(\mathrm{P}_{6,6,6,14} \mathrm{Cl}\right)$ (Cytec Ltd) and diphenylphosphoric acid (Aldrich, Australia). The $\mathrm{P}_{1,4,4,4} \mathrm{dpp}$ was synthesized by the reaction of tributhyl(methyl)phosphonium methylcarbonate (CYPHOS $® I L \quad 340$ ) with diphenyl 
phosphoric acid (Aldrich, Australia). The $\left[\mathrm{P}_{6.666,14}\right]\left[\left({ }^{\mathrm{i}} \mathrm{C}_{8}\right)_{2} \mathrm{PO}_{2}\right]$ with purity of $\geqslant 95 \%$, was purchased from Sigma-Aldrich.

The ILs were purified before use. Purification was performed by first dissolving them in high purity liquid chromatography (HPLC) grade acetone and adding activated charcoal before passing them through a column containing a filter agent (fine $\mathrm{SiO}_{2}$ ), and basic activated alumina to remove the impurities. The solution was then passed through filter paper and a syringe filter. Excess acetone and water were evaporated using a rotary evaporator and a vacuum line. The water content of the ILs after purification was $500-1000$ ppm (measured using a Model 756 Karl Fischer Coulometer (Metrohm)).

A Simulated Body Fluid (SBF) was used as the corrosion test solution due to its similar ionic composition to that of human blood plasma. It contains $103 \mathrm{mM} \mathrm{Cl}^{-}, 147 \mathrm{mM} \mathrm{Na}^{+}, 2.6 \mathrm{mM}$ $\mathrm{Ca}^{2+}, 1.5 \mathrm{mM} \mathrm{Mg}^{2+}, 5 \mathrm{mM} \mathrm{K}^{+}, 6 \mathrm{mM} \mathrm{HCO}_{3}{ }^{-}, 0.5 \mathrm{mM} \mathrm{SO}_{4}{ }^{2-}$, and $1 \mathrm{mM} \mathrm{HPO}_{4}{ }^{2-}$. The $\mathrm{pH}$ of the SBF was 7.4, which was maintained with HEPES buffer (2-[4-(2-hydroxyethyl)-1piperazin-1-yl] ethanesulfonic acid (Ajax Finechem) at a concentration of $17.892 \mathrm{~g} / \mathrm{L}$.

\subsection{Cytotoxicity Tests.}

The cytotoxicity of the ILs was determined using a primary human coronary artery endothelial cell (HCAEC) line. Cells were obtained from Lonza (Australia) and maintained in growth medium containing SingleQuot supplements (Lonza, Australia). The cells were added to a 12 well testing plate at a density of $1.5 \times 10^{4}$ cells $/ \mathrm{cm}^{2}$. The ILs were added to the cell culture medium at different concentrations $(200 \mathrm{mM}, 50 \mathrm{mM}, 10 \mathrm{mM}, 5 \mathrm{mM}, 1 \mathrm{mM}, 0.1 \mathrm{mM}$, $10 \mu \mathrm{M}, 1 \mu \mathrm{M}, 0.1 \mu \mathrm{M}, 0.01 \mu \mathrm{M})$. After 72 hours culture on the plates, the numbers of adherent cells were quantified. HCAEC cells grown in standard cell culture medium were used as the control.

\subsection{In Situ Electrochemical Impedance Spectroscopy (EIS) Tests using Pipette Cell.}


A pipette cell was used to conduct in situ measurements of the IL film formation on the surface of $\mathrm{AZ31}$ at $100^{\circ} \mathrm{C}$.[21] With this setup, the pipette was clamped onto the sample surface; a small amount of IL (approximately $0.3 \mathrm{~mL}$ ) was added into the pipette to cover the surface. A heat-shrink-wrapped platinum $(\mathrm{Pt})$ wire was used as the pseudo-reference electrode, and titanium mesh was counter electrode.

EIS spectra were acquired at 30-minute intervals for 24 hours, over a frequency range of 500 $\mathrm{kHz}$ to $100 \mathrm{mHz}$, with eight points per decade and a $25 \mathrm{mV}$ amplitude perturbation, using an Bio-logical VP 3/Z multi-channel potentiostat. Caution was taken to keep the distance the same between the reference and working electrodes, in order to keep the solution resistance consistent between tests.

\subsection{Attenuated Total Reflectance Sampling used with Fourier Transform Infrared Spectroscopy (ATR-FTIR).}

ATR-FTIR was performed on a Varian 3100 Excalibur Series Spectrometer using Varian Resolutions Pro Version 4.1 software. Scans (at $10 \mathrm{kHz}$ with a resolution of $4 \mathrm{~cm}^{-1}$ and a sensitivity of 8) were made on pure IL $\mathrm{P}_{1,4,4,4} \mathrm{dpp}$ and selected IL treated samples for comparison.

\subsection{Raman Spectral Mapping.}

Raman spectral mapping was acquired using a Renishaw Raman Spectrophotometer. The maps were taken from the surfaces of AZ31s after 1 hour and 5 hours IL treatment at $100^{\circ} \mathrm{C}$, over a sample size of approximately $100 \mu \mathrm{m}$ x $150 \mu \mathrm{m}$. Maps were generated at chosen Raman shifts $\left(\sim 1076 \mathrm{~cm}^{-1}\right)$.

\subsection{Focused Ion Beam Scanning Electron Microscopy (FIB-SEM).}

The cross-section of the IL film was characterized using a FEI Quanta 3D FIB-SEM instrument. Gallium ions were used to section the surface with a $5 \mathrm{nA}$ current, and to clean 
the edge of the cross section with $3 \mathrm{nA}$ and $1 \mathrm{nA}$ currents. A platinum layer was deposited onto the surface prior to the milling to protect the edge of the milled section. The crosssection was then imaged using secondary electron SEM at an accelerating voltage of $5 \mathrm{kV}$.

The sample was acid pickled AZ31 with 1 hour IL treatment at $100^{\circ} \mathrm{C}$. The acid pickled treatment was achieved by immersion of the alloy sample in $80 \mathrm{~mL} / \mathrm{L} \mathrm{HNO}_{3}$ for 1 minutes at room temperature.

\subsection{Scanning Electrochemical Microscopy (SECM).}

Scanning electrochemical microscopy (SECM) was performed using a $\mathrm{CH}$ instruments model 920D SECM, utilizing CHI integrated software Version 12.26. Pt disk ultra-micro-electrode (UME) with a $10 \mu \mathrm{m}$ diameter (purchased from $\mathrm{CH}$ instruments Inc.) was used as working electrodes, Pt mesh was used as counter electrode, and $\mathrm{Ag} / \mathrm{AgCl}$ was the reference electrode.

SECM maps were carried out using Surface Generation/Tip Collection (SG/TC) mode (or Hydrogen Evolution (HE) mode). In this mode, UME potential was biased at $0.0 \mathrm{~V}(\mathrm{Ag} / \mathrm{AgCl})$ to electro-oxidize $\mathrm{H}_{2}$ thus detecting the $\mathrm{H}_{2}$ flux from the surface of $\mathrm{Mg}$ during corrosion process.

\subsection{Corrosion Tests in Static SBF.}

2.8.1 Electrochemical impedance spectroscopy (EIS) tests.

EIS measurements were performed in a modified plastic three-electrode cell containing 150 $\mathrm{mL}$ of SBF, with saturated calomel reference (SCE) electrode and titanium mesh counter electrode. Data were taken at 10-min intervals for approximately 2.5 hours over a frequency range of $50 \mathrm{kHz}$ to $50 \mathrm{mHz}$ with 8 points per decade, using a $10 \mathrm{mV}$ AC amplitude perturbation. 
The EIS measurements were performed using a Bio-logic VMP 3/Z, and repeated in triplicate to indicate the reproducibility of results. The Z-fit program in EC-Lab software was used to fit an equivalent circuit to the EIS spectra

\subsubsection{Immersion tests.}

As polished and IL treated AZ31 samples were immersed into $100 \mathrm{~mL}$ SBF at $37^{\circ} \mathrm{C}$ for 2 hours. All immersion tests were performed in triplicate. After testing, the corrosion morphologies of the samples were examined using a Philips XL20 Scanning Electron Microscopy (SEM), with an accelerating voltage of $10 \mathrm{KeV}$.

The corrosion products were removed by immersion for 2 mins in a solution containing $200 \mathrm{~g}$ chromium trioxide, $10 \mathrm{~g}$ silver nitrate and $20 \mathrm{~g}$ barium nitrate in $1 \mathrm{~L}$ of distilled water at room temperature. After the removal of corrosion products, the surfaces were analysed using a Veeco Contour GT-K1 Optical Profilometry (OP), which counted the pit numbers at each pit depth over a $937.5 \mu \mathrm{m} \times 1250 \mu \mathrm{m}$ area. Four or more points on each sample were examined, and the pit numbers and pit depths were expressed as mean \pm standard deviation (SD).

\subsection{Potentiodynamic polarization (PP) tests in flowing SBF.}

Tests in "flowing" conditions were performed in a customized flow cell, which has been described in detail in Zhang et al.[23] The volume of solution used for each test was $100 \mathrm{~mL}$, which constantly flushed over the surface of the sample. The flow condition expressed as the shear stress applied on the surface of sample was with a shear stress of $0.88 \mathrm{~Pa}$, which is similar to those in human blood vessel.[24]

PP tests were performed after recording the open circuit potential for 24 hours, at a scan rate of $1 \mathrm{mV} / \mathrm{s}$, sweeping from $-100 \mathrm{mV}$ vs. $E_{\text {ocv }}$ to $500 \mathrm{mV}$ vs. $E_{\text {ocv. }} E_{\text {corr }}$ and $i_{\text {corr }}$ values were obtained by Tafel extrapolation of the PP curves. At least 3 measurements were obtained per test, which were used to determine the mean value \pm standard deviation (SD). 


\section{RESULTS AND DISCUSSION}

\subsection{Cytotoxicity of ILs.}

Figure 2 compares the HCAEC cell viability after 72 hours culture with several concentration of various ILs. The results indicate that $\mathrm{P}_{1,4,4,4} \mathrm{dpp}$ did not show significant cytotoxicity to HCAEC cells (at the concentration lower than $1 \mathrm{mM}$ ). While $\mathrm{P}_{6,6,6,14} \mathrm{dpp}$ appeared to be toxic to HCAEC cells even at 1,000 times lower concentration $(1 \mu \mathrm{M})$. From Figure 2, the toxicity level of the three ILs are ranked as follows: $\mathrm{P}_{1,4,4,4} \mathrm{dpp}$ (least toxic) $>\left[\mathrm{P}_{6,6,6,14}\right]\left[\left({ }^{\mathrm{i}} \mathrm{C}_{8}\right)_{2} \mathrm{PO}_{2}\right]>$ $\mathrm{P}_{6,6,6,14} \mathrm{dpp}$ (most toxic). The difference is believed to be related to the fact that $\mathrm{P}_{6,6,6,14} \mathrm{dpp}$ is more lipophilic/hydrophobic than $\mathrm{P}_{1,4,4,4} \mathrm{dpp}$ and $\left[\mathrm{P}_{6,6,6,14}\right]\left[\left({ }^{\mathrm{i}} \mathrm{C}_{8}\right)_{2} \mathrm{PO}_{2}\right]$, and the lipophilic interaction between $\mathrm{P}_{6,6,6,14} \mathrm{dpp}$ and HCAEC cell membrane would lead to the disruption of the membrane of cells, and thus the death of cells.[15, 25, 26] Based on this result, $\mathrm{P}_{1,4,4,4} \mathrm{dpp}$ appears to be the most promising candidate of the three, with the lowest impact on coronary artery cells in the human body. Therefore, further investigations in this study were focused on this $\mathrm{P}_{1,4,4,4} \mathrm{dpp}$ IL for the protective surface coating application on AZ31.

\subsection{Evaluation of IL Film Growth at $100^{\circ} \mathrm{C}$ using A Pipette Cell via EIS.}

To investigate the evolution of the surface coating when AZ31 was treated in the $\mathrm{P}_{1,4,4,4} \mathrm{dpp}$ IL over a 24 hours period, the EIS data was recorded at 30-min intervals using the pipette cell setup. Figure 3 (a) is the typical Nyquist plot of the EIS data obtained. There is only one arc observed in all spectra; this arc is believed to correspond to the surface coating. In these spectra, both real $(Z)$ and imaginary (Z') parts of impedance were increasing with treatment time. Moreover, it seems that the film impedance increased quickly at the beginning of treatment, and then stabilized as time continued.

To quantify the evaluation of the surface film, a simplified Randle's circuit (Figure 3b) was used to fit these spectra.[12] In this equivalent circuit, $R_{s}$ is the solution resistance of the IL between the reference electrode and the working electrode in the pipette cell; $\mathrm{Q}_{\mathrm{f}}$ is a constant 
phase element $\left(Q_{f}\right)$ representing the film capacitance in parallel with a surface film resistance $\left(R_{f}\right)$. This equivalent circuit provided a good fit to the experimental data with $x^{2} \approx 7 \mathrm{e}^{-3}$.

Figure 3(c) plots the surface film resistance obtained from fitting the Randle circuit as a function of immersion time throughout the 24 hours of IL treatment. The surface film resistance increased rapidly in the first 5 hours of treatment, and then reached a plateau. This increase reflected the growth of the IL film on AZ31 surface over time. Thus, it can be concluded that the optimum film resistance to provide the optimized corrosion control is achieved after 5 hours treatment at $100^{\circ} \mathrm{C}$. Prolonging the treatment will not significantly increase the resistance of the formed IL surface film, and thus should not change the corrosion protection properties of the film.

\subsection{Film Characterization.}

FTIR analysis was carried out to determine the differences in the absorbance spectra of IL treated samples with different treatment times (Figure 4). A significant feature of difference between the FTIR spectra for an IL-treated AZ31 surface and for the pure IL is observed. A new peak at $\sim 1076 \mathrm{~cm}^{-1}$ was evident in the spectrum of the IL treated substrate compared with that of the pure IL. The presence of this peak on the IL treated AZ31 surface is an indicator for the existence of IL film on the surface, which suggests the formation of a metal ester $\left[\mathrm{Mg}-\mathrm{O}-\mathrm{PO}_{2}\right]^{-}$between the IL film and the metal substrate.[13] The FTIR spectra from the IL-treated AZ31 surfaces as a function of treatment time are also compared in Fig. 4. The intensity of the peak corresponding to the [Mg-O-PO2-] ester group increased with increasing treatment time, indicating that there was an increase in the extent of IL film formation with the longer treatment. The FTIR data suggest that more extensive IL surface film was formed with the longer IL treatment time, which response to the EIS analysis (Figure 3).

The presence of the peak at $\sim 1076 \mathrm{~cm}^{-1}$ was also observed in the Raman spectroscopy of IL treated AZ31 surfaces. To further compare the distribution of the IL coatings on AZ31 after 
different IL treatment times and to gain insight into the IL coating formation process, Raman spectral mapping based on $\sim 1076 \mathrm{~cm}^{-1}$ band (which corresponds to the ester group) was taken on the surface of AZ31 samples after 1 hour and 5 hours IL treatment, and the obtained raman spectral maps are shown in Figure 5. As shown in Figure 5, the distribution of this chemical species on the surface after 1 hour IL treatment was almost similar to the grain boundary structure of AZ31. There was a greater concentration of this species in the regions around grain boundaries. Compared to the surface after 1 hour treatment, the 5 hours of IL treated alloy appeared to have a higher concentration of ester groups on its surface. A significant amount of ester groups were not only distributed around the grain boundaries but also over the entire grains.

To further understand the influence of alloy microstructure on the formation of IL surface film the AZ31 was acid pickled in $\mathrm{HNO}_{3}$ for 1 minute to protrude its microstructure before the IL treatment. Figure 6 shows the FIB-SEM observation of the cross-section of the IL film formed after 1 hour IL treatment. The bright area in this figure is Pt deposition, and the IL film corresponds to the dark area between Pt deposition and $\mathrm{Mg}$ substrate. This figure shows evidence of the preferential deposition of the IL coating adjacent to intermetallic particles (which are mostly deposited along the grain boundaries). There was a non-uniform deposition of the IL film on the surface, with significantly thicker film formation around intermetallic particles, compared to that on the $\mathrm{Mg}$ matrix.

\subsection{In Vitro Corrosion Properties of IL Treated Surfaces in Static SBF.}

EIS was also used to compare the corrosion behaviour. The spectra were taken at 10-min intervals for 2.5 hours during exposure of treated samples to the SBF solution. Figure 7 (a) shows a typical evolution of Nyquist impedance spectra as a function of exposure time for AZ31 treated with IL for 5 hours. In these spectra, there are two semi-circles. The high frequency (HF) semicircles (to the left of the figure) were due to the surface film, and the low 
frequency (LF) semicircles were due to the double layer capacitance.[13, 22] Both HF and LF semicircles increased in size with immersion time. This increase is due to a gradual build-up of calcium apatite-like corrosion products on the surface, which results in an increase of both the surface film resistance and charge transfer resistance.[22] Therefore, the evolution of these Nyquist plots can reflect the corrosion process of the sample during immersion in SBF.

A simplified equivalent circuit (Figure 7(b)) was chosen to fit these EIS spectra, for a quantitative comparison of corrosion performance. The circuit consists of an electrolyte resistance, $R_{s}$, and two $R C$ units in series, representing the surface film $\left(R_{f}\right.$ and $\left.Q_{f}\right)$ and the double layer $\left(\mathrm{R}_{\mathrm{t}}\right.$ and $\left.\mathrm{C}_{\mathrm{dl}}\right)$. To study the corrosion behaviour, the surface film resistances were extracted by fitting this equivalent circuit to the HF semicircles. Figure 7 (c) plots the variation of the surface film resistances with respect to immersion time for the AZ31s that had been treated with IL with different times. Compared with 10 mins and 1 hour IL treated AZ31, the 5 hours IL treated AZ31 showed the highest initial surface film resistance (at $t=0$ hour) and the least increase in surface film resistance with immersion time, suggesting that a longer treatment ( 5 hours) formed a surface film with higher film resistance, which could offer better corrosion protection to the $\mathrm{Mg}$ substrate in the SBF. It is important to note here that while the surface resistance of the other samples continued to increase, this is as a result of corrosion products continuing to form and deposit on the surface leading to higher resistances; it does not imply improved corrosion resistance. On the other hand, the plateau reached for the 5 hours treatment time implies a more uniform and stable surface. This does not mean that the corrosion is stopped, but merely that the corrosion rate is more controlled as shown further below, which is promising for biodegradable Mg implant application.

Figure 8 shows the corroded surfaces of samples treated with IL $10 \mathrm{~min}, 1$ and 5 hours, after immersion in SBF for 2 hours. On the surfaces of 10 mins and 1 hour IL treated AZ31 samples, there were numerous white and hemi-spherical caps. We believe these caps were the result of localized pitting corrosion. In comparison, the surface of 5 hours IL treated AZ31 
was neat, and there were fewer white caps observed. These observations suggest that 5 hours IL treated surface was less susceptible to localized pitting corrosion.

In order to evaluate the corrosion morphology in detail, corrosion products were removed from the surfaces and then further examined using optical profilometer. Figure 9 (a) shows typical three-dimensional surface observations of these samples. The 10 mins and 1 hour IL treated AZ31 surfaces appeared to be heavily attacked by localized pitting corrosion with some portions of the surfaces corroded away. After 5 hours IL treatment, the AZ31 surface was significantly less corroded. There were only a few shallow pits observed on its surface. Figure 9 (b) shows a more quantitative comparison of the corrosion severity by indicating the number of pits at each pit depth obtained by OP. This histogram confirms that the longer treatment $(5$ hours) produced a surface with more corrosion resistance. In particular, the difference is more evident in pits that were deeper than $10 \mu \mathrm{m}$. For example, in the 10-15 $\mu$ m size range, there were $\sim 100$ pits $/ \mathrm{mm}^{2}$ on the surface of the 5 hours IL treated AZ31 surface, which is a significant reduction compared to the 10 mins IL treated AZ31 that had 400 pits $/ \mathrm{mm}^{2}$. From Figure 8 and 9, it is evident that the film produced by the IL treatment for 5 hours effectively prevented localized deep pitting corrosion, and produced a more uniform mode of corrosion attack.

\subsection{Characterization of in situ Corrosion Performance using SG/TC Mode SECM.}

\section{Background}

As known, the corrosion process of AZ31 in aqueous solution generates $\mathrm{H}_{2}$, mainly by Reaction 1 (shown below). In SECM SG/TC mode, generated $\mathrm{H}_{2}$ is sensed via an oxidation reaction, either by Reactions 2 or 3, depending on the $\mathrm{pH}$ of the solution adjacent to the tip of SECM.[27] By scanning the $\mathrm{H}_{2}$ evolution from the AZ31 surface, SECM can evaluate the sensitivity and reactivity of the sample surface to corrosion. In this work, as corrosion of $\mathrm{Mg}$ 
generates a localized alkaline environment, Reaction 3 dominates the hydrogen consumption at the SECM tip at high $\mathrm{pH}$ environment.

Reaction 1: $\mathrm{Mg}+2 \mathrm{H}_{2} \mathrm{O}=\mathrm{Mg}^{2+}+2 \mathrm{OH}^{-}+\mathrm{H}_{2} \uparrow$

Reaction 2: $H_{2}=2 H^{+}+2 e^{-}$

Reaction 3: $\mathrm{H}_{2}+2 \mathrm{OH}^{-}=2 \mathrm{H}_{2} \mathrm{O}+2 e^{-}$

SG/TC Mode SECM Maps

Firstly, SECM tests were carried out at the beginning of exposure of AZ31 samples to the 100-fold diluted SBF. As the concentration of ions in this electrolyte was low, the surfaces were considered to have undergone negligible corrosion. The SECM maps obtained in this situation can reflect the initial corrosion activities of the surfaces. The tested samples were as polished, 1 hour and 5 hours IL treated samples, as shown in Figure 10. In this figure, the tip current values corresponded to the $\mathrm{H}_{2}$ evolution rate from the surfaces. The points showing higher tip current values were the areas undergoing greater reduction of water to hydrogen gas, and thus there was more severe corrosion occurring in these areas.

In Figure 10, the SECM map for the as polished AZ31 shows a non-uniform distribution of the tip currents over the surface, reflecting non-homogeneous corrosion reactivity occurring on the surface of the as polished sample. There was a large region with lower current observed at the bottom of the surface, suggesting slower corrosion activity in this area. The current density of this top part is almost 5 times more than the bottom part, indicating that this area behaves more anodically. With the consideration that the native oxide layer of $\mathrm{Mg}$ alloy $\mathrm{AZ31}\left(\mathrm{Mg}(\mathrm{OH})_{2} / \mathrm{MgO}\right)$ is not a robust insulating film in $\mathrm{Cl}^{-}$containing aqueous solution, the low corrosion reactivity in this region was most likely due to this area being cathodically protected by localized corrosion occurring at other areas of the sample for example the top of the sample shown in the figure. 
By comparison, obvious differences were observed on the IL treated samples. The SECM maps of these IL treated samples appeared to be more homogeneous than the as polished sample. Thus, IL treatment makes corrosion occurring more uniformly on the surface. In addition, it is promising to note that the 5 hours IL treated sample showed an almost featureless SECM map, indicating that corrosion occurred uniformly over the entire surface.

A more realistic study of the corrosion performance of these samples was also conducted using SG/TC mode SECM. Figure 11 shows the SECM maps of the surfaces after being immersed in SBF solutions for 1 hour. The as polished AZ31 surface showed evidence of severe localized pitting corrosion; while the IL treated surfaces (in particular the surface with 5 hours IL treatment) exhibited a more homogeneous distribution of tip currents across the surface, indicating a more uniform corrosion response. Moreover, compared with the as polished AZ31, the IL treated surfaces exhibited lower values of tip currents, indicating lower corrosion rates on these surfaces in SBF.

These SECM maps are real-time evidence of lower corrosion rate and more uniform corrosion reactivity on the IL treated surfaces, than on the as polished surface.

\subsection{Corrosion Performance of Treated (5 hours in IL) AZ31 in Flowing Conditions.}

It is apparent the AZ31 IL treated for 5 hours has shown promising corrosion protection performance in static SBF. To further investigate if this IL treatment could provide continuous effective corrosion protection under hydrodynamic conditions, as polished AZ31 samples and AZ31 treated with IL for 5 hours were immersed in a flowing SBF for 24 hours. PP scans were collected after this time, and are shown in Figure 12.

As shown in figure 12, the PP curve of IL treated AZ31 showed lower cathodic and anodic current densities than that of the as polished AZ31. The PP curve of the IL treated AZ31 also showed a large passive (i.e. flat) region in the anodic arm, while the anodic arm of the PP curve for as polished AZ31 was much steeper. This observation suggests that the IL treated 
AZ31 surface was more resistive to the pitting corrosion than the as polished AZ31. The $\mathrm{i}_{\text {corr }}$ and $\mathrm{E}_{\text {corr }}$ values were calculated by Tafel extrapolation (Table 1). Corrosion rate, $\mathrm{i}_{\text {corr }}$, for IL treated sample was decreased by a factor of almost 10 compared with $\mathrm{i}_{\text {corr }}$ for the as polished sample. Overall, it is promising to see that the 5 hours IL treated AZ31 showed much better corrosion performance in flowing SBF, as compared to the as polished AZ31.

\subsection{Effect of Treatment Time on the IL Film Formation and Its Corrosion Performance.}

On the basis of the surface characterizations by FTIR, Raman spectral maps and FIB-SEM, it is speculated that the formation of $\mathrm{P}_{1,4,4,4} \mathrm{dpp}$ IL film on AZ31 was a progressive process. At the beginning of the IL treatment, a film deposited on the surface preferentially, mainly adjacent to some of the regions next to intermetallic particles. With the time increasing, the IL film gradually spread from these reactive regions over the whole surface area.

The corrosion experiments suggest that after IL treatment, the corrosion performance of $\mathrm{Mg}$ alloy was enhanced with a significant decrease in the localized pitting corrosion. This corrosion phenomenon corresponds to the IL film formation process. For bare AZ31, severe localized pitting corrosion occurs mostly adjacent to the intermetallic particles on the surface due to the galvanic potential difference between these particles and $\mathrm{Mg}$ matrix. The IL film is deposited preferentially around intermetallic particles, which makes the regions around these particles less prone to corrosion attack in the solution. Therefore, the sample after IL treatment is less sensitive to localized pitting corrosion.

It thus appears that the IL treatment time plays an important role in controlling the rate and morphology of corrosion on AZ31, and the treatment processing conditions are key to ensuring an optimum protective film. In this study, 5 hours IL treatment at elevated treatment temperature $\left(100^{\circ} \mathrm{C}\right)$ was found to provide good corrosion protection for AZ31 in SBF.

\section{CONCLUSIONS}


The cytotoxicity of three phosphate-based ILs $\left(\mathrm{P}_{6,6,6,14} \mathrm{dpp},\left[\mathrm{P}_{6.6 .614}\right]\left[\left({ }^{\mathrm{i}} \mathrm{C}_{8}\right)_{2} \mathrm{PO}_{2}\right]\right.$ and $\left.\mathrm{P}_{1,4,4,4} \mathrm{dpp}\right)$ was tested. Of these three ILs, hydrophilic IL $\mathrm{P}_{1,4,4,4} \mathrm{dpp}$ showed promising low toxicity to the primary human coronary artery endothelial cell (HCAEC). The formation process of this $\mathrm{P}_{1,4,4,4}$ dpp IL film on AZ31 surface at $100^{\circ} \mathrm{C}$ was evaluated in a three-electrode pipette cell arrangement. Comprehensive surface characterizations and corrosion performances were further evaluated. The results indicate that prolonging the treatment to 5 hours would significantly increase the resistance of the formed IL surface coating. After 5 hours IL treatment, the surface became more passive and chemically homogeneous. Of all samples, AZ31 IL treated for 5 hours showed the most promising corrosion performance with the lowest corrosion rate and homogeneous corrosion morphology, which corresponds well with the surface characterization results. The corrosion performance of AZ31 after 5 hours IL treatment was further examined in a flowing SBF, and the result showed that it maintained its corrosion protection under hydrodynamic conditions. It seems that the formation of $\mathrm{P}_{1,4,4,4} \mathrm{dpp}$ IL film on AZ31 has proceeded progressively. A film deposited on the surface preferentially, mainly adjacent to some of the regions next to intermetallic particles. With the increased treatment time, the IL film gradually spread from these reactive regions over the entire surface. Therefore, treatment time plays an important role. The time must be long enough to form a robust and homogeneous film. Given all these characteristics, this simple chemical surface modification using low toxic $\mathrm{P}_{1,4,4,4} \mathrm{dpp}$ by this treatment method ( 5 hours at $100^{\circ} \mathrm{C}$ ), shows significant promise to further investigate as a surface coating for biodegradable $\mathrm{Mg}$ based devices. Future objectives include undertaking the cytotoxicity test and in-vivo test on this IL-coated sample as well as pursuing new chemistries to reduce the temperature and times needed for optimum protection using IL based procedures. 
The authors would like to acknowledge Boston Scientific and the ARC for funding through the Centre of Excellence for Electromaterials Science (ACES) Linkage (project no. LP0990621). Acknowledgement is also given to Dr. Jiazeng Sun (Monash University) for preparing the ILs; Dr. Jan Weber (Boston Scientific), and Dr. Torsten Scheuermann (Boston Scientific) for valuable discussion and comments; Deakin Electron Microscopy center to allowing using their SEM. GGW and MF acknowledge the ARC for their Laureate Fellowships.

\section{REFERENCES}

[1] W.D. Müller, M.L. Nascimento, M. Zeddies, M. Córsico, L.M. Gassa, M.A.F.L.d. Mele, Magnesium and its alloys as degradable biomaterials: corrosion studies using potentiodynamic and EIS electrochemical techniques, Mat. Res., 10 (2007) 5-10.

[2] M. Forsyth, P.C. Howlett, S.K. Tan, D.R. MacFarlane, N. Birbilis, An lonic Liquid Surface Treatment for Corrosion Protection of Magnesium Alloy AZ31, Electrochem. Solid-State Lett., 9 (2006) B52-B55. [3] F. Witte, The history of biodegradable magnesium implants: A review, Acta Biomater, 6 (2010) 1680-1692.

[4] E. Ghali, W. Dietzel, K.-U. Kainer, General and localized corrosion of magnesium alloys: A critical review, J. Mater. Eng. Perform., 13 (2004) 7-23. 
[5] S.-H. Ye, Y.-S. Jang, Y.-H. Yun, V. Shankarraman, J.R. Woolley, Y. Hong, L.J. Gamble, K. Ishihara, W.R. Wagner, Surface Modification of a Biodegradable Magnesium Alloy with Phosphorylcholine (PC) and Sulfobetaine (SB) Functional Macromolecules for Reduced Thrombogenicity and Acute Corrosion Resistance, Langmuir, 29 (2013) 8320-8327.

[6] R. Erbel, C. Di Mario, J. Bartunek, J. Bonnier, B. de Bruyne, F.R. Eberli, P. Erne, M. Haude, B. Heublein, M. Horrigan, C. Ilsley, D. Böse, J. Koolen, T.F. Lüscher, N. Weissman, R. Waksman, Temporary scaffolding of coronary arteries with bioabsorbable magnesium stents: a prospective, non-randomised multicentre trial, The Lancet, 369 1869-1875.

[7] X.B. Chen, N. Birbilis, T.B. Abbott, Review of Corrosion-Resistant Conversion Coatings for Magnesium and Its Alloys, Corrosion, 67 (2011) 1-16.

[8] H. Hornberger, S. Virtanen, A.R. Boccaccini, Biomedical coatings on magnesium alloys - A review, Acta Biomater, 8 (2012) 2442-2455.

[9] J.E. Gray, B. Luan, Protective coatings on magnesium and its alloys - a critical review, J. Alloys Compd., 336 (2002) 88-113.

[10] A. Zomorodian, M.P. Garcia, T. Moura e Silva, J.C. Fernandes, M.H. Fernandes, M.F. Montemor, Corrosion resistance of a composite polymeric coating applied on biodegradable AZ31 magnesium alloy, Acta Biomater, 9 (2013) 8660-8670.

[11] N. Birbilis, P.C. Howlett, D.R. MacFarlane, M. Forsyth, Exploring corrosion protection of Mg via ionic liquid pretreatment, Surf. Coat. Technol., 201 (2007) 4496-4504.

[12] J. Efthimiadis, W.C. Neil, A. Bunter, P.C. Howlett, B.R. Hinton, D.R. MacFarlane, M. Forsyth, Potentiostatic control of ionic liquid surface film formation on ZE41 magnesium alloy, ACS Appl. Mater. Interfaces, 2 (2010) 1317-1323.

[13] Y. Zhang, M. Forsyth, B.R.W. Hinton, The Effect of Treatment Temperature on Corrosion Resistance and Hydrophilicity of an lonic Liquid Coating for Mg-Based Stents, ACS Appl. Mater. Interfaces, 6 (2014) 18989-18997.

[14] K. Fujita, D.R. MacFarlane, M. Forsyth, Protein solubilising and stabilising ionic liquids, Chem. Commun., 38 (2005) 4804-4806.

[15] R.F. Frade, C.A. Afonso, Impact of ionic liquids in environment and humans: an overview, Hum Exp Toxicol, 29 (2010) 1038-1054.

[16] R. Ferraz, L.C. Branco, C. Prudencio, J.P. Noronha, Z. Petrovski, lonic liquids as active pharmaceutical ingredients, ChemMedChem, 6 (2011) 975-985.

[17] M. Seter, M.J. Thomson, J. Stoimenovski, D.R. MacFarlane, M. Forsyth, Dual active ionic liquids and organic salts for inhibition of microbially influenced corrosion, Chem. Commun., 48 (2012) 59835985.

[18] A.G. Santos, B.D. Ribeiro, D.S. Alviano, M.A.Z. Coelho, Toxicity of ionic liquids toward microorganisms interesting to the food industry, RSC Adv, 4 (2014) 37157-37163.

[19] S.P. Ventura, A.M. Goncalves, T. Sintra, J.L. Pereira, F. Goncalves, J.A. Coutinho, Designing ionic liquids: the chemical structure role in the toxicity, Ecotoxicology (London, England), 22 (2013) 1-12. [20] J.-A. Latham, P.C. Howlett, D.R. MacFarlane, M. Forsyth, Passive film formation in dilute ionic liquid solutions on magnesium Alloy AZ31, Electrochem. Commun., 19 (2012) 90-92.

[21] P.C. Howlett, T. Khoo, G. Mooketsi, J. Efthimiadis, D.R. MacFarlane, M. Forsyth, The effect of potential bias on the formation of ionic liquid generated surface films on Mg alloys, Electrochim. Acta, 55 (2010) 2377-2383.

[22] Y.F. Zhang, B. Hinton, G. Wallace, X. Liu, M. Forsyth, On corrosion behaviour of magnesium alloy AZ31 in simulated body fluids and influence of ionic liquid pretreatments, Corros Eng Sci Techo , 47 (2012) 374-382.

[23] Y. Zhang, B.R.W. Hinton, F. Maria, A flow cell for using electrochemical techniques to monitor the corrosion process of $\mathrm{Mg}$ alloys in flowing simulated body fluid, Unpublished, DOI.

[24] J. Levesque, H. Hermawan, D. Dube, D. Mantovani, Design of a pseudo-physiological test bench specific to the development of biodegradable metallic biomaterials, Acta Biomater, 4 (2008) 284-295.

[25] S. Stolte, M. Matzke, J. Arning, A. Boschen, W.-R. Pitner, U. Welz-Biermann, B. Jastorff, J. Ranke, Effects of different head groups and functionalised side chains on the aquatic toxicity of ionic liquids, Green Chem., 9 (2007) 1170-1179. 
[26] T.P. Thuy Pham, C.-W. Cho, Y.-S. Yun, Environmental fate and toxicity of ionic liquids: A review, Water Res., 44 (2010) 352-372.

[27] S.S. Jamali, S.E. Moulton, D.E. Tallman, M. Forsyth, J. Weber, G.G. Wallace, Evaluating the corrosion behaviour of Magnesium alloy in simulated biological fluid by using SECM to detect hydrogen evolution, Electrochim. Acta, 152 (2015) 294-301. 
Table 1. $E_{\text {corr }}$ and $i_{\text {corr }}$ values of as polished AZ31 and 5 hours IL treated AZ31 after immersion in a flowing SBF for 1 hour, obtained by Tafel extrapolation of the PP curves.

\begin{tabular}{|l|l|l|}
\hline Samples & $\mathrm{E}_{\text {corr }}(\mathrm{V}$ v.s. SCE) & $\mathrm{i}_{\text {corr }}\left(\mu \mathrm{A} / \mathrm{cm}^{2}\right)$ \\
\hline As polished AZ31 & $-1.3 \pm 0.02$ & $13.8 \pm 0.4$ \\
\hline 5 hours IL treated AZ31 & $-1.5 \pm 0.05$ & $1.4 \pm 0.25$ \\
\hline
\end{tabular}


Figure Captions

Figure 1. Chemical structure of $\mathrm{P}_{6,6,6,14}{ }^{+}$cation, $\mathrm{P}_{1,4,4,4}{ }^{+}$cation, dpp ${ }^{-}$anion and $\left[\left({ }^{\mathrm{i}} \mathrm{C}_{8}\right)_{2} \mathrm{PO}_{2}\right]^{-}$ anion.

Figure 2. Primary human coronary artery endothelial cell (HCAEC) viabilities after 72 hours in IL-containing culture media.

Figure 3. (a) A typical Nyquist plot of EIS obtained during IL treatment in a pipette cell at $100^{\circ}$ C. (b) Simplified EIS equivalent circuit used to fit EIS data, $R_{s}, R_{f}, Q_{f}$ are the solution resistance, film resistance and constant phase element corresponding to the film, respectively. (3) The change of the surface film resistance with respect to the treatment time with the dashed vertical line indicating the minimum time required to achieve optimum film resistivity.

Figure 4. FTIR spectra of neat IL (P1,4,4,4dpp) and IL treated AZ31s with various treatment time.

Figure 5. Typical Raman maps of AZ31 surfaces after (a) 1 hour and (b) 5 hours IL treatment, based on the $1076 \mathrm{~cm}^{-1}$ band (which corresponds to the symmetric stretch of $\mathrm{PO}_{2}^{-}$in $(\mathrm{RO})_{2} \mathrm{PO}_{2}^{-}$(salt).

Figure 6. FIB-SEM observation of cross-section of the IL film formed on $\mathrm{HNO}_{3}$ acid pickled AZ31 after 1 hour IL treatment.

Figure 7. (a) A typical Nyquist plot of EIS obtained during immersion 5 hours IL treated AZ31 in SBF solution at $37^{\circ} \mathrm{C}$. (b) Simplified EIS equivalent circuit used to fit EIS data, $\mathrm{R}_{\mathrm{s}}$, $\mathrm{R}_{\mathrm{f}}, \mathrm{Q}_{\mathrm{f}}, \mathrm{R}_{\mathrm{t}}$ and $\mathrm{C}_{\mathrm{dl}}$ are the solution resistance, film resistance, constant phase element corresponding to the film, charge transfer resistance and double layer capacitance, respectively. (3) The variation of the surface film resistance as a function of immersion time for alloy treated with IL for various time. 
Figure 8. Typical SEM observations of IL treated AZ31 samples after 2 hours immersion in $100 \mathrm{~mL} \mathrm{SBF}$ at $37^{\circ} \mathrm{C}$. These samples are 10 mins IL treated A31, 1 hour IL treated A31, and 5 hours IL treated A31, respectively.

Figure 9. (a) Typical OP observations of AZ31 surfaces after the removal of corrosion products. (b) Histogram of pit distributions (the number of pits at different pits depths per surface area of $937.5 \mu \mathrm{m} \times 1250.0 \mu \mathrm{m}$ ); the samples are 10 mins IL treated AZ31, 1 hour IL treated AZ31, and 5 hours IL treated AZ31, respectively.

Figure 10. SECM maps obtained at the beginning of exposure to the 100 -fold diluted SBF, for the as-polished AZ31, 1 hour IL treated AZ31 and 5 hours IL treated AZ31, respectively.

Figure 11. SECM maps obtained after exposure to SBF for 1 hour, for the as-polished AZ31, 1 hour IL treated AZ31 and 5 hours IL treated AZ31.

Figure 12. PP scans of as polished AZ31 and 5 hours IL treated AZ31 after 24 hours immersion in a flowing SBF. 
Figure 1:

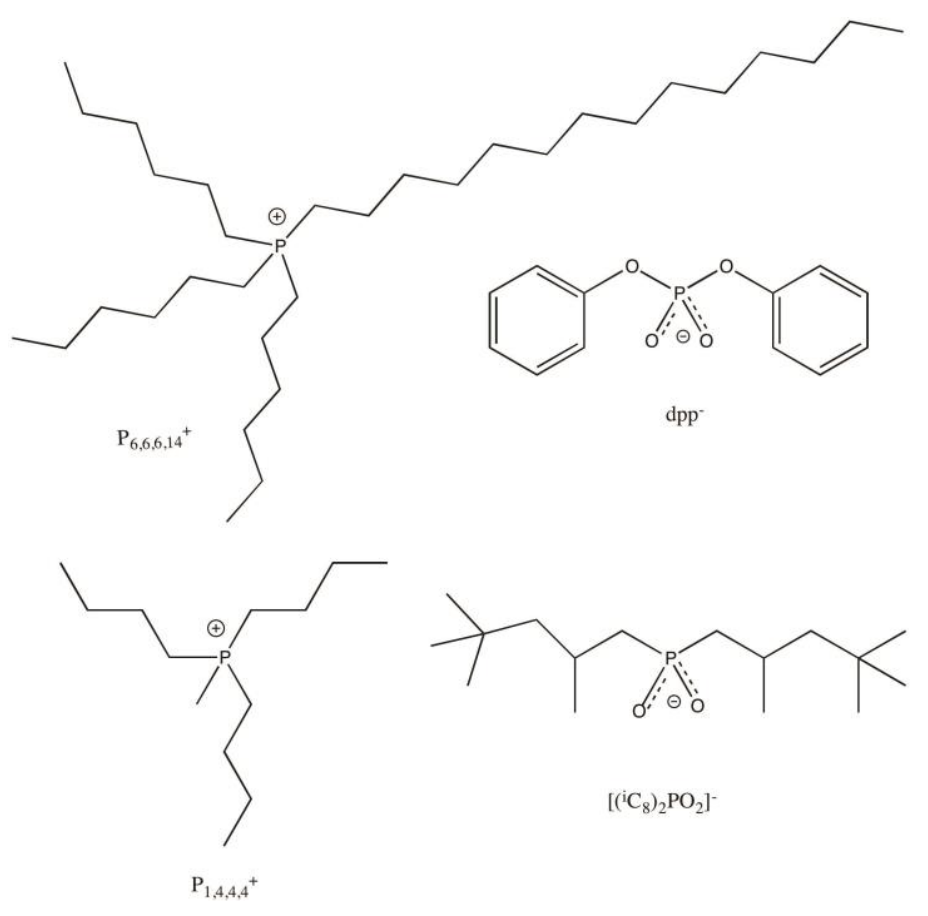

Figure 2:

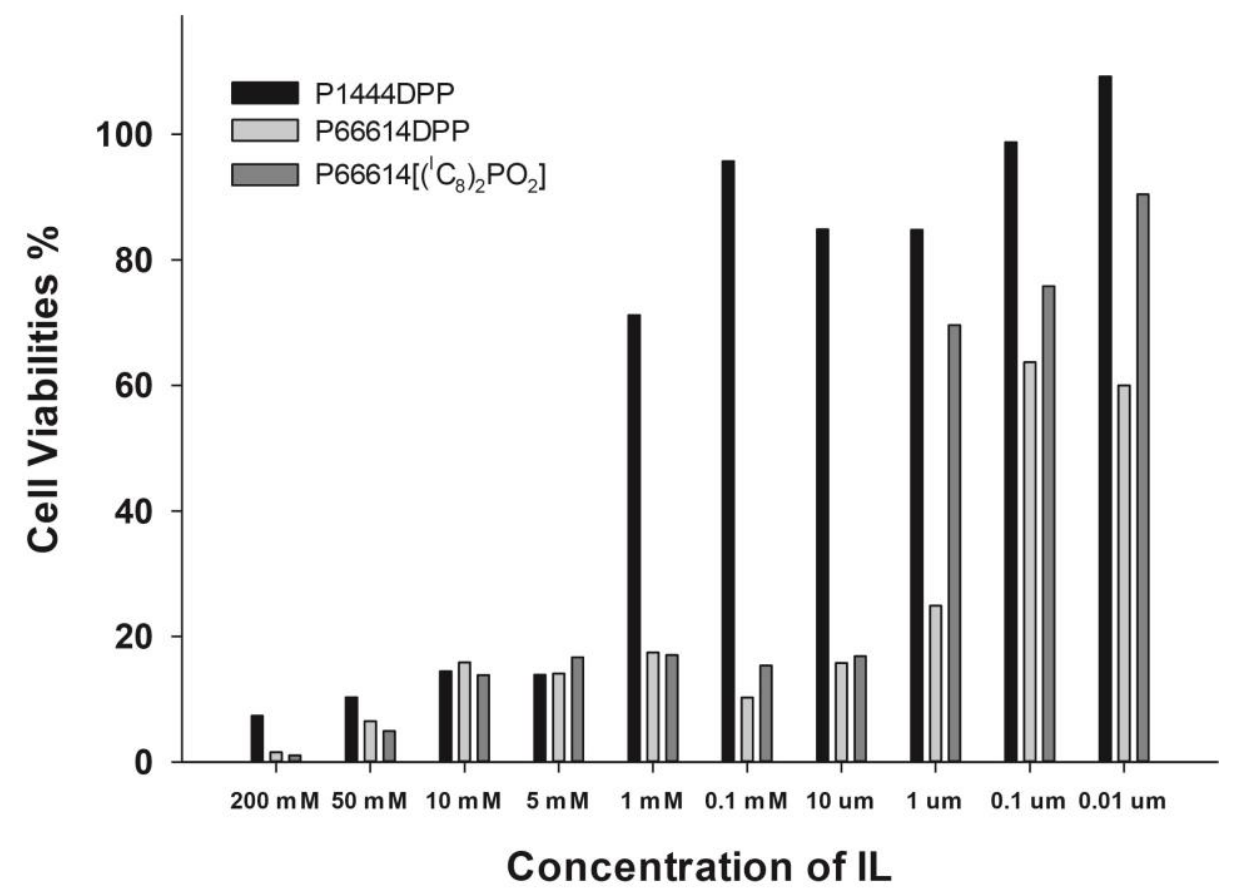


Figure 3:

(a)

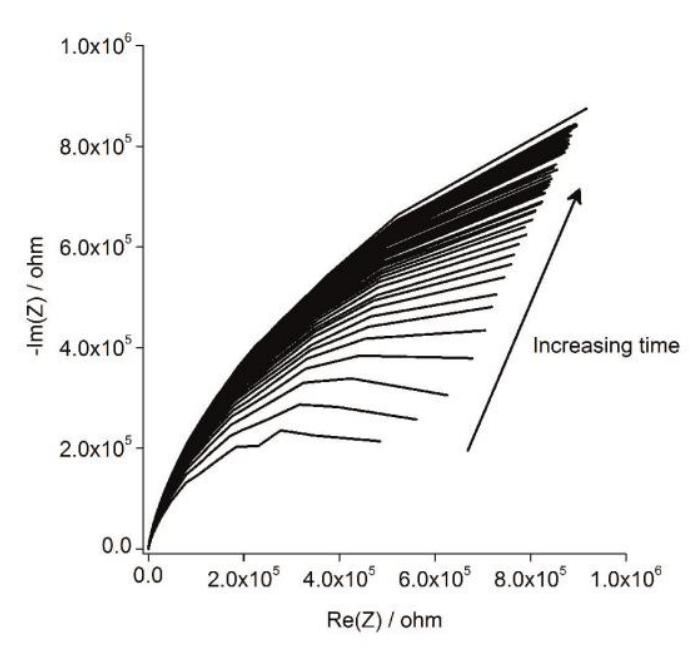

(b)

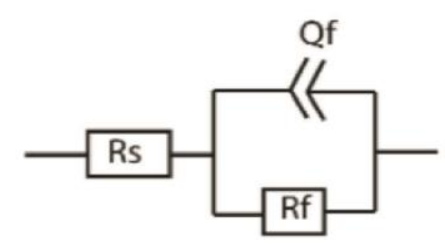

(c)

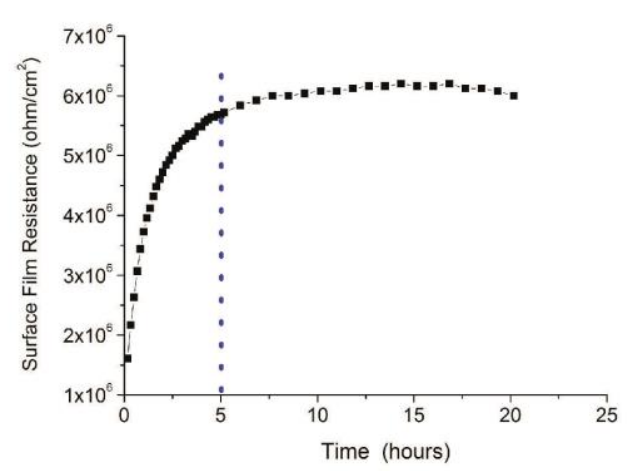

Figure 4:

Peak intensity increases with increasing treatment time
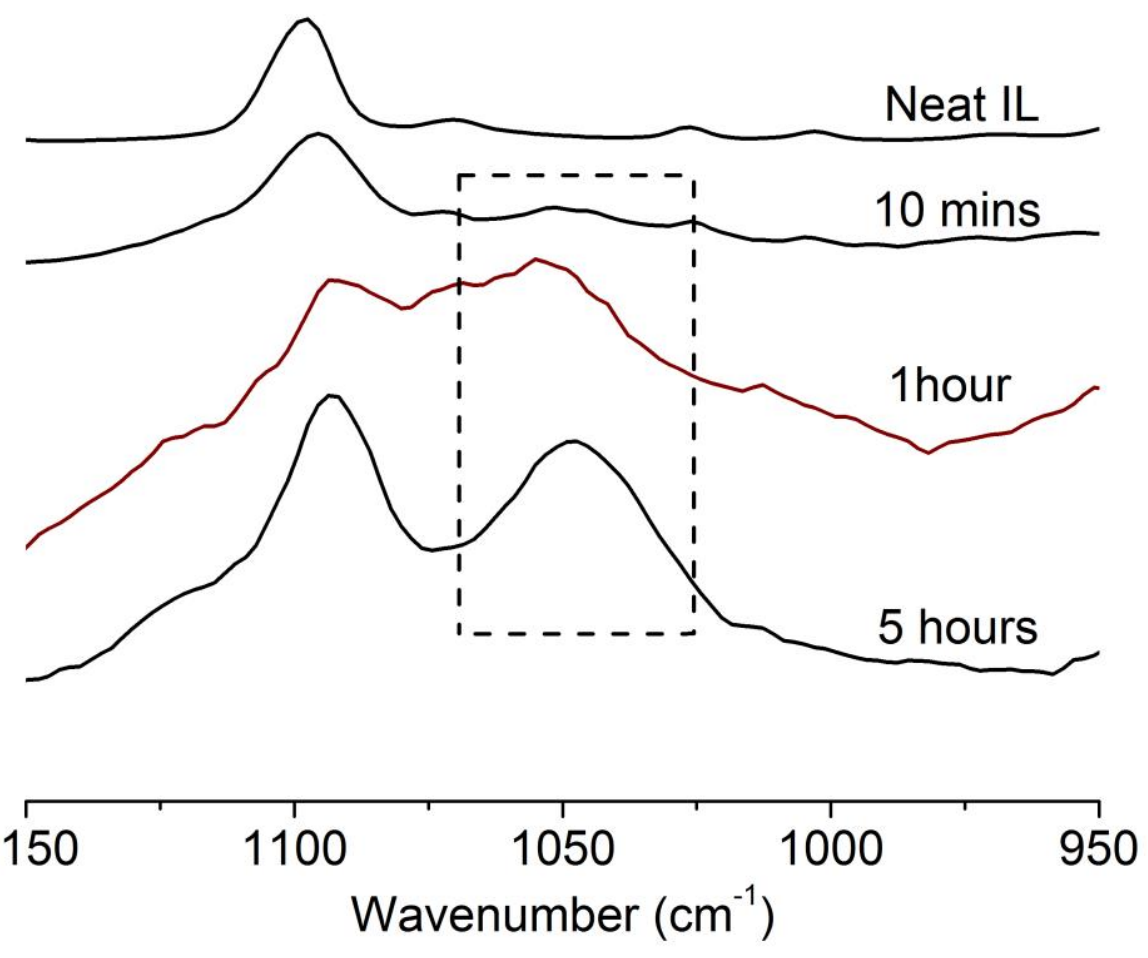


\section{Figure 5:}

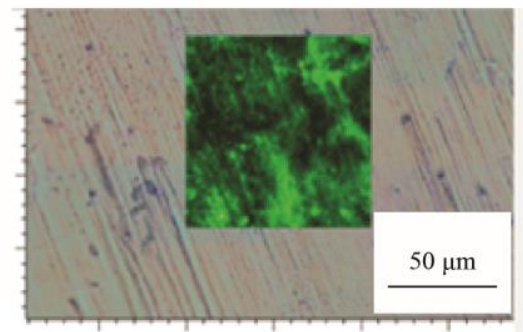

1 hour IL treated AZ31 Surface

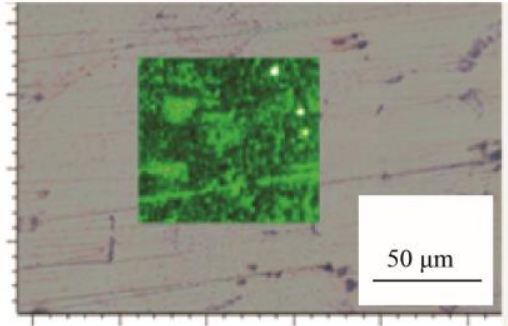

5 hours IL treated AZ31 surface

\section{Figure 6:}

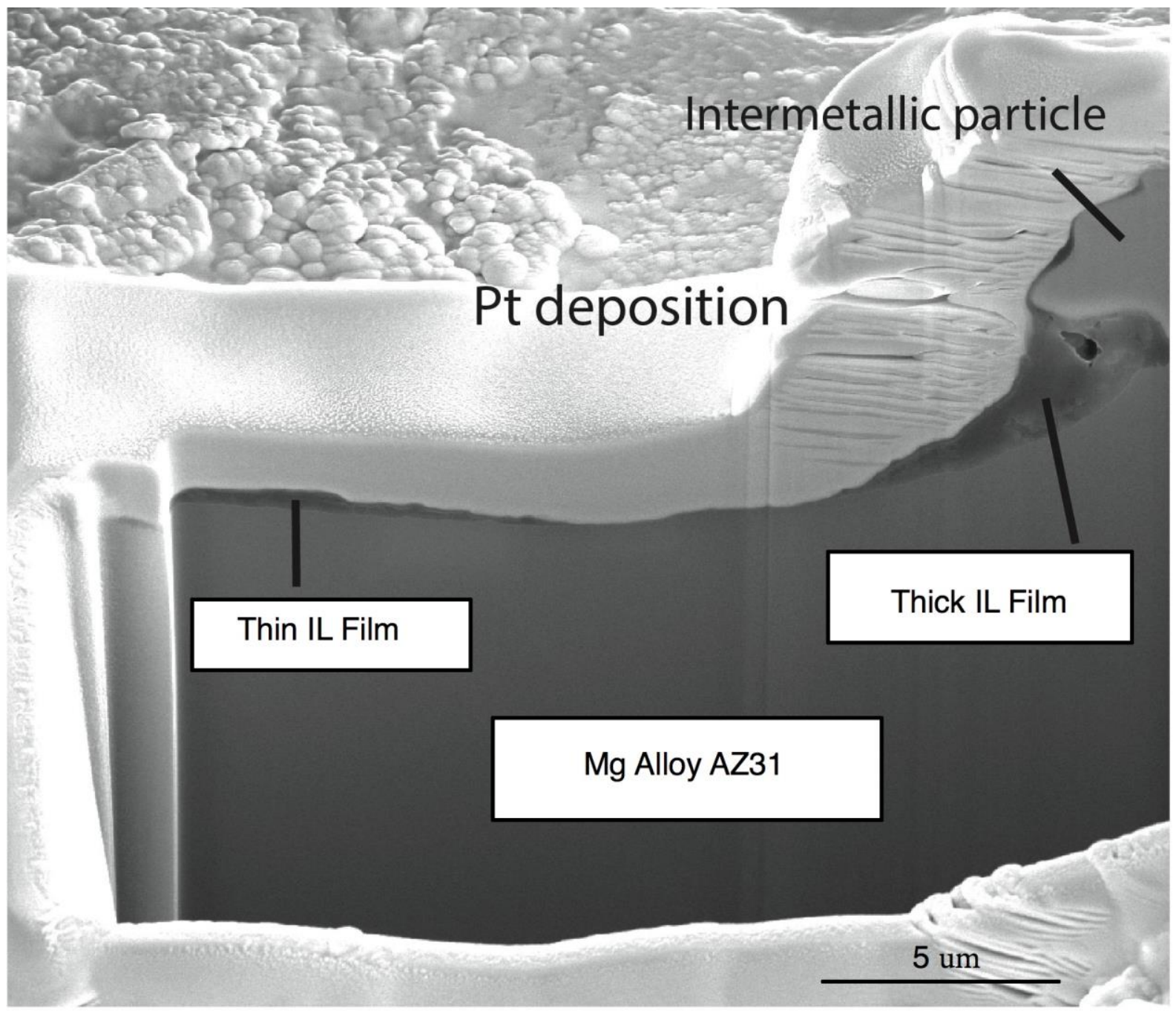




\section{Figure 7:}

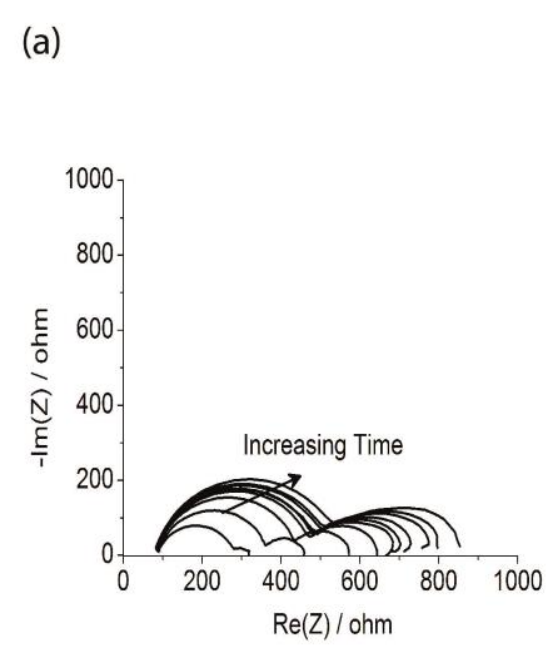

(b)

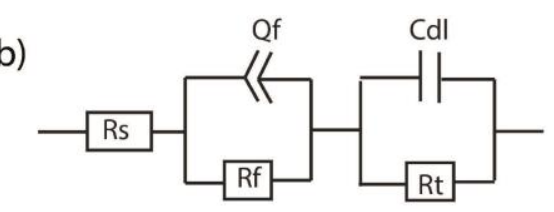

(c)

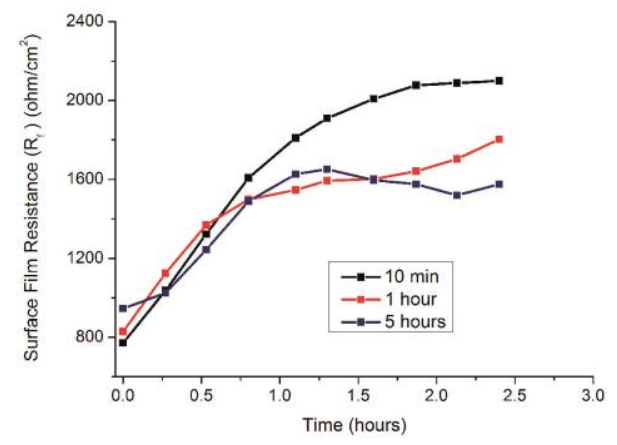

Figure 8:
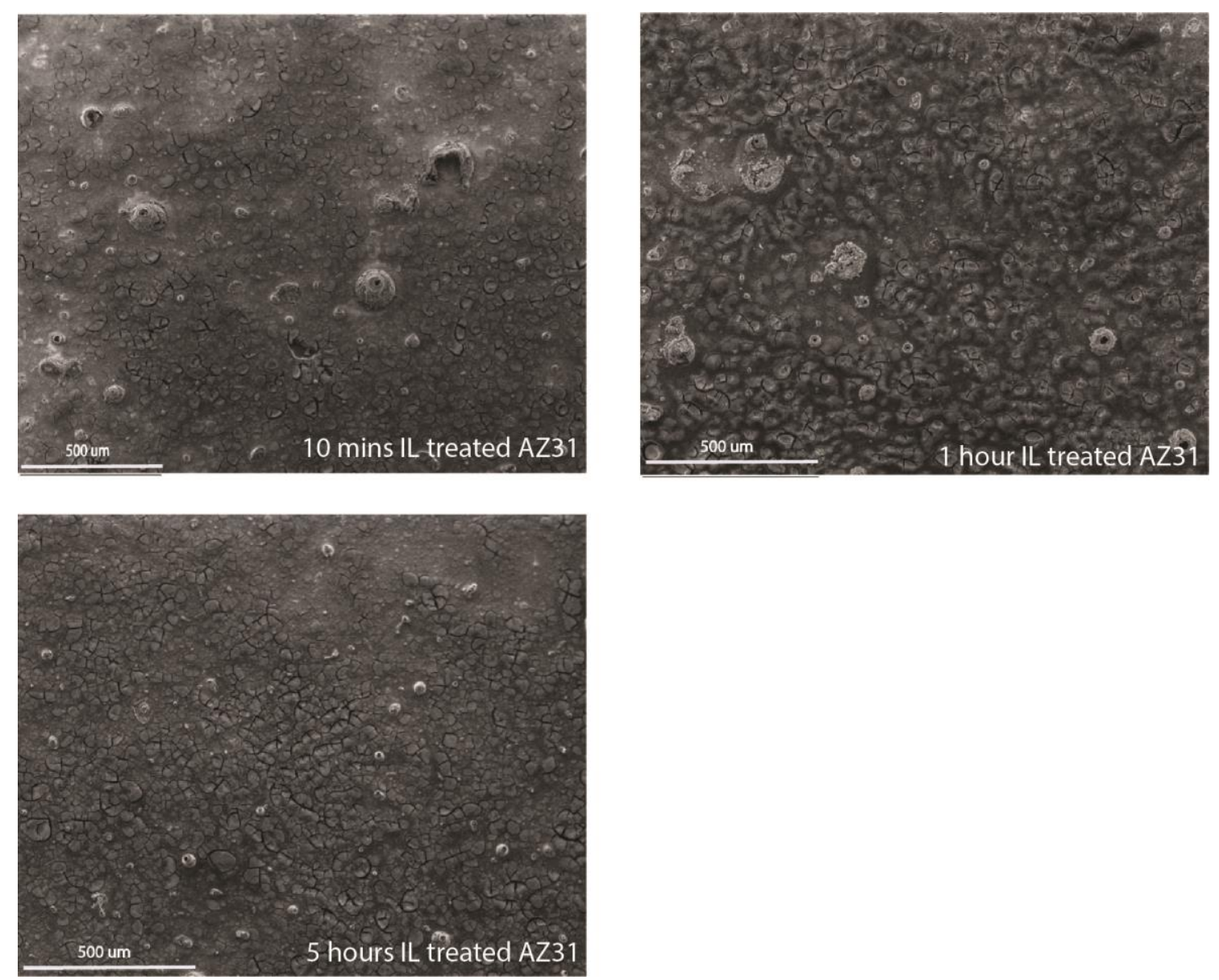


\section{Figure 9:}
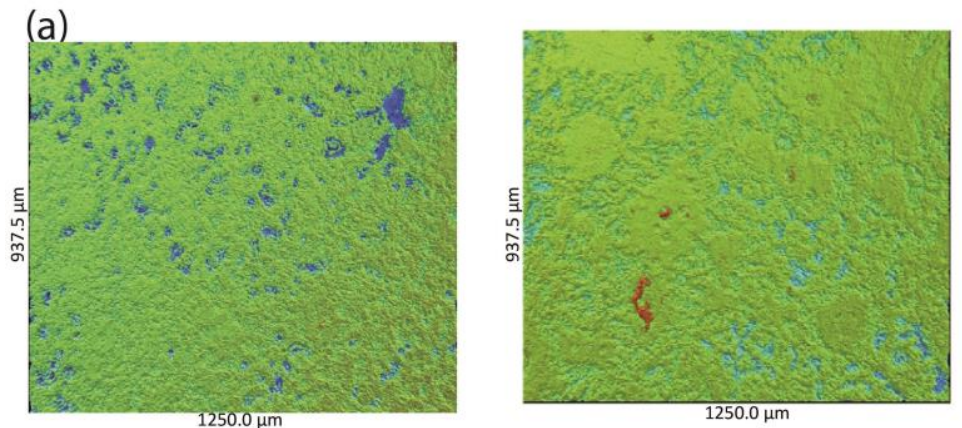

10 mins IL treated AZ31

1hour IL treated AZ31
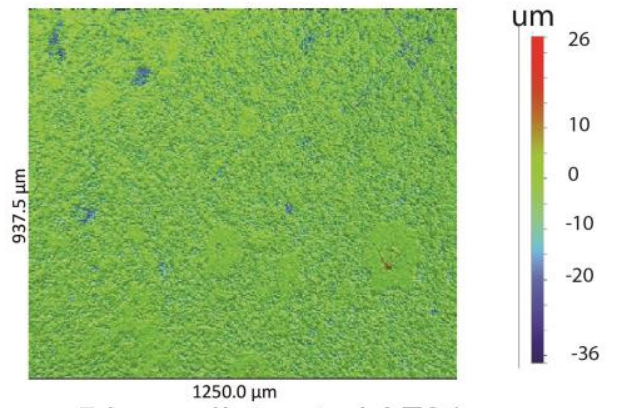

5 hours IL treated $A Z 31$

(b)

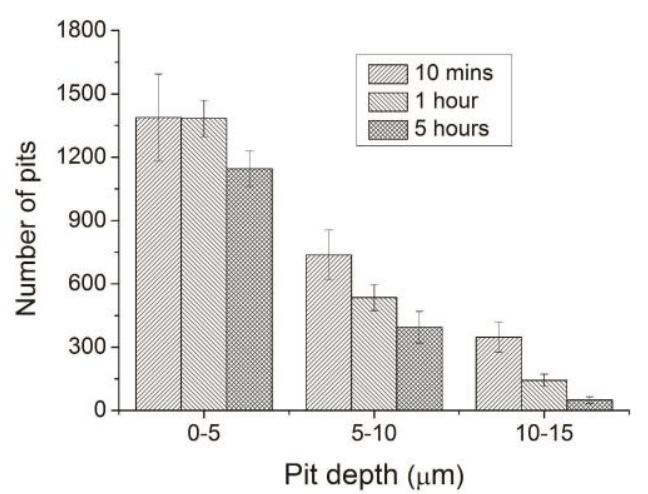


Figure 10:

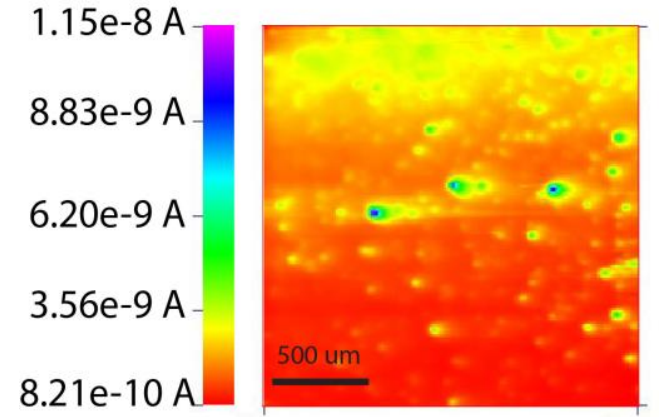

As polished AZ31

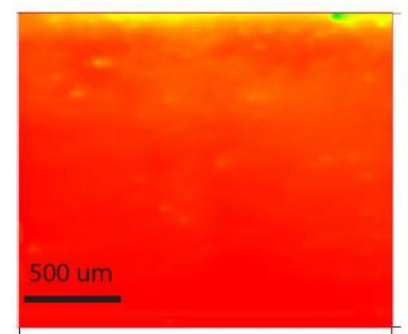

5 hours IL treated AZ31

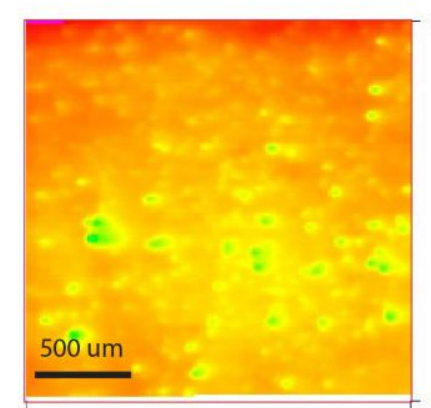

1 hour IL treated AZ31

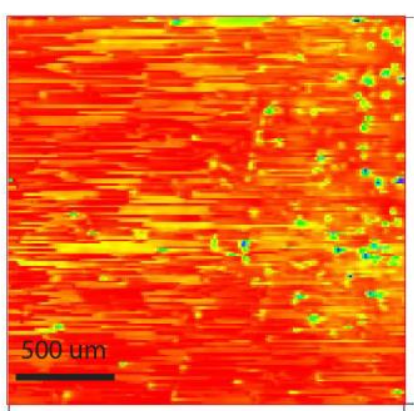

1 hour IL treated AZ31

Figure 11:

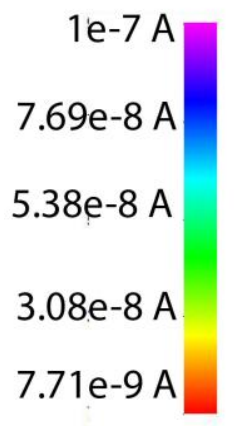

As polished

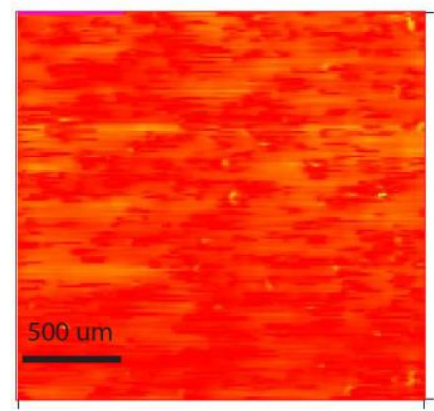

5 hours IL treated AZ31 
Figure 12:

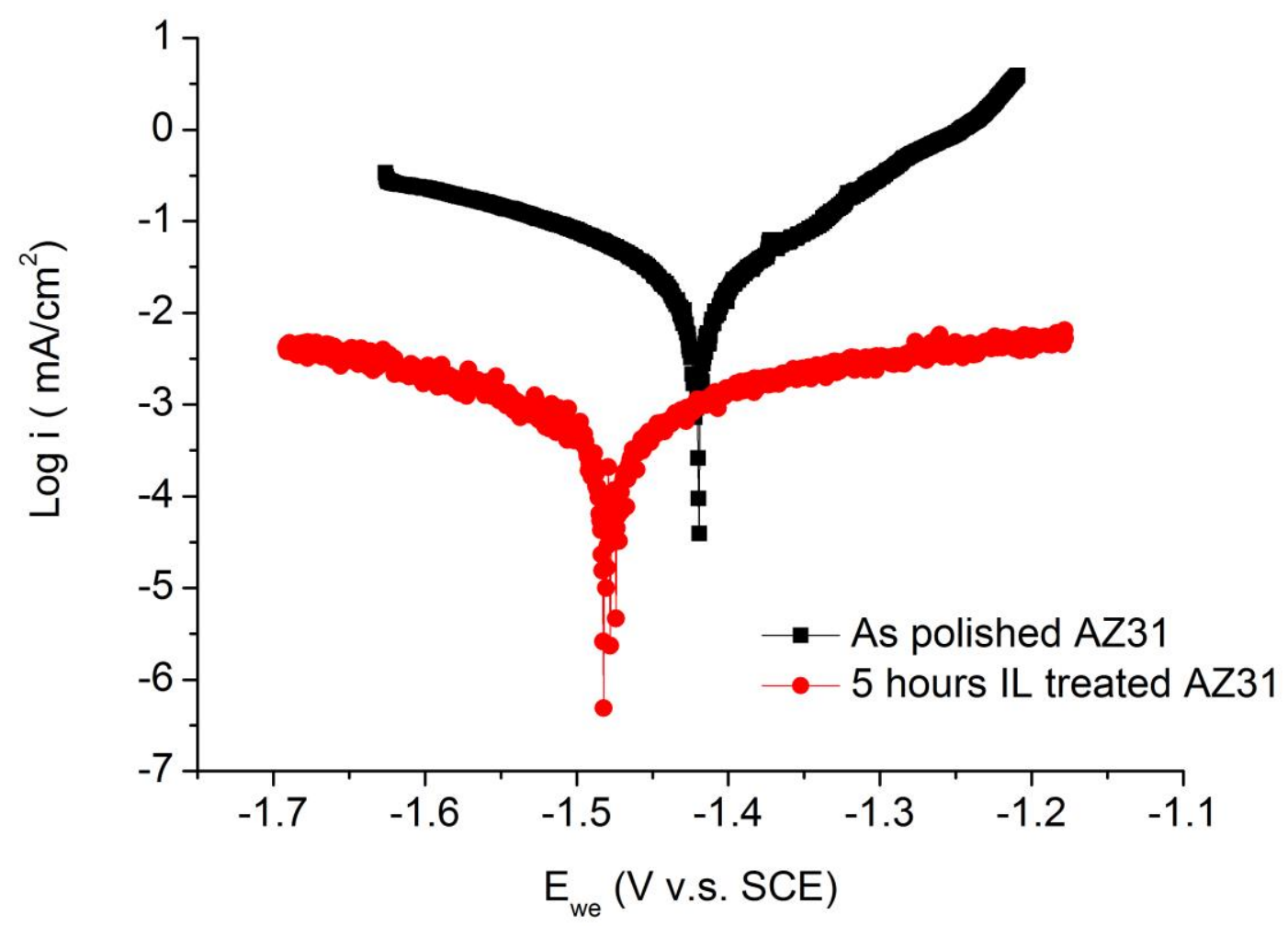

